\title{
NBS
}

Eechnical Note

no. 19

Boulder Laboratories

\section{ANALYSIS OF IONOSPHERIC VERTICAL SOUNDINGS FOR ELECTRON DENSITY PROFILE DATA}

II. EXTRAPOLATION OF OBSERVED ELECTRON DENSITY PROFILES ABOVE $h_{\text {max }} \mathrm{F} 2$

BY J.W. WRIGHT

U. S. DEPARTMENT OF COMMERCE NATIONAL BUREAU OF STANDARDS 



\title{
NATIONAL BUREAU OF STANDARDS Eechnical Mote
}

19

June 1959

\begin{abstract}
ANALYSIS OF IONOSPHERIC VERTICAL SOUNDINGS FOR ELECTRON DENSITY PROFILE DATA
\end{abstract}

II. Extrapolation of Observed Electron Density Profiles Above $h_{\text {max }} \mathrm{F2}$

by

J. W. Wright

NBS Technical Notes are designed to supplement the Bureau's regular publications program. They provide a means for making available scientific data that are of transient or limited interest. Technical Notes may be listed or referred to in the open literature. They are for sale by the Office of Technical Services, U. S. Department of Commerce, Washington 25, D. C.

\section{DISTRIBUTED BY \\ UNITED STATES DEPARTMENT OF COMMERCE \\ OFFICE OF TECHNICAL SERVICES}

WASHINGTON 25, D. C.

Price $\$ .50$ 

ANALYSIS OF IONOSPHERIC VERTICAL SOUNDINGS

FOR ELECTRON DENSTTY PROFILE DATA

II. Extrapolation of Observed Electron Density Profiles Above $h_{\max } \mathrm{F2}$

By J.W. Wright

Central Radio Propagation Laboratory

Abstract

A tentative model of the $F$ region above $h_{\max }$ is provided to permit extrapolation of electron density profiles into this reglon. The model corresponds to a simple "Chapman" curve, and may be fitted to true height data (obtained in part I) by a simple graphical process. 

EXTRAPOLATION OF OBSERVED ELECTRON DENSITY PROFIIES

$\mathrm{ABOVE} \mathrm{h}_{\max } \mathrm{F}_{2}$

by

J. W. Wright

Central Radio Propagation Laboratory

\section{Introduction}

Frequently the application of electron density profiles to certain problems requires information concerning the portion of the profile above the peak electron density of the $F_{2}$ layer. The following are two typical examples of such problems:

A) A space probe is to be launched to the planet venus. The launching rocket "burns out" at an altitude of $520 \mathrm{~km}$ above a point $300 \mathrm{~km}$ northeast of Cape Canaveral. Just preceding that instant, the radio guidance devices at the launching site must know with great accuracy the speed, direction, and position of the vehicle so that final corrections may be made on these quantities for a satisfactory trajectory. What is the electron density at the point in question, and what is its profile along a line of sight between the vehicle and the launching site, so that allowance may be made for ionospheric re= fraction of the radio signals?

B) An earth satellite has just been launched and is in a satisfactory but imprecisely known orbit. Orbital data may be obtained by the well known method of doppler observations, but accurate measurements require a correction involving the electron density at the satellite 
and the integrated density between the satellite and the terrestrial recelver. This satellite is never below an altitude of $680 \mathrm{~km}$. How may the necessary 1onospheric data be provided?

A partial solution of these problems is provided by the network of lonospheric sounding stations. From the soundings, a reasonably accurate electron density profile may be deduced; the accuracy depends somewhat upon the location desired, the proximity of sounding stations to that 1ocation, and the extent to which an adequate "history" of profiles for that region exists.

Unfortunately, such "true height" determination can give only the profile up to the peak electron density; no observational data is provided by the sounding, concerning higher levels. If the desired level is above the peak, some form of extrapolation of the observations is necessary to solve the problem.

It is the purpose of this report to describe such a standard extrapolation and to provide the means for making it. A study of the properties of the proposed extrapolation and comparison with available observational data has indicated (Wright, 1959) that the chosen model corresponds closely to currently available evidence on the most likely distribution above the peak density of the Ionosphere. 


\section{The Extrapolation Model}

It has been found that a model of the lonosphere given by the well known "Chapman" expression

$$
\begin{gathered}
N=N_{\max } \exp 1 / 2\left(1-z-e^{-z}\right), \\
z=\frac{h-h_{\max }}{H},
\end{gathered}
$$

gives a satisfactory fit to the avallable observational data above $h_{\max }$ (height of $\mathrm{N}_{\max }$, the peak electron density), if $\mathrm{H}$, the "scale height" of the substance ionized is taken as $100 \mathrm{~km}$. This equation expresses the electron density $\mathbb{N}$ as a function of height $h$, throughout the layer. Of course, it is only proposed to use this model for values of h greater than $h_{\max }$. In terms of the ordinary-ray observing frequency, or plasma frequency $f_{\mathbb{N}}, E q .(1)$ may be written:

$$
f_{N} / f_{N_{\max }}=\exp 1 / 4\left(1-z-e^{-z}\right)
$$

where $\mathbb{N}$ is related to $f_{\mathbb{N}}$ by

$$
\mathbb{N}\left(\text { electrons } / \mathrm{cm}^{3}\right)=12,400 \mathrm{f}_{\mathrm{N}}^{2} \text {, }
$$

where $f_{\mathbb{N}}$ is measured in $\mathrm{Mc} / \mathrm{s}$, 
With the adopted choice of $\mathrm{H}=100 \mathrm{~km}$, we obtain from this expression the following values of $\mathrm{fN} / \mathrm{f}_{\mathrm{N}_{\max }}$

\begin{tabular}{cl}
$\mathrm{h}-\mathrm{h}_{\max }$ & $\mathrm{fN} / \mathrm{f}_{\mathbb{N}_{\max }}$ \\
\hline 20 & 0.995 \\
50 & 0.974 \\
100 & 0.912 \\
200 & 0.753 \\
300 & 0.599 \\
400 & 0.470 \\
500 & 0.367 \\
600 & 0.286 \\
700 & 0.223 \\
800 & 0.174 \\
900 & 0.135 \\
1000 & 0.105
\end{tabular}

These values are plotted on the standard $N(h)$ graph paper (form $N-5$ ) shown in figure 1. Because of the semi-logarithmic frequency scale, this curve has the same "shape" wherever it is placed on the scale. By plotting at the beginning of a logarithmic cycle (i.e. for $f^{\prime} N_{\max }$ at $10 \mathrm{Mc}$ ), the graph may be used as a "slide rule" for the extrapolation of observed curves, as discussed in the next section.

\section{Application}

The extrapolation curve may be used to determine the above-peak profile of any ionosphere for which the peak electron density (or the ordinary penetration frequency, foF $\left.2=f_{N_{\max }}\right)$, and the height of the peak $\left(h_{\max }\right)$ are known. The basic method of application is the following: Suppose foF2 and $h_{\max }$ are known (for example by application of a manual $N(h)$ method, as in NBS Technical Note No.14, or perhaps the 
complete profile is available up to $h_{\max }$ from the results of machlne computation). The value of foF 2 and $h_{\max }$, or the complete profile, should be plotted on Standard $N(h)$ graph paper, form $N-4$ (fig. 2). If form $\mathrm{N}-5$ is placed over form $\mathrm{N}-4$, so that the point $(\mathrm{h}=0, \mathrm{f}=10$ ) on $N-5$ is coincident with the point ( $h_{\max }, f \circ 2$ ) on $N-4$, with the height scales parallel, then the extrapolation curve gives the desired "topside" extrapolation. It may be useful to cut the form $\mathrm{N}-5$ along the extrapolation line if it is desired to trace the extrapolation onto the form $\mathrm{N}-4$.

\section{Determination of Integrated Electron Content}

The Chapman model employed here permits a fairly convenient determination of its integrated electron content. This is useful particularly If the integrated content up to $h_{\max }$ is also available from a complete electron density profile; then a combination of the observations with the model gives an estimate of the electron content up to any level.

The total electron content up to $a$ height $h$, obtained by integrating equation 1 , is the following:

$$
N_{h}=\int_{-\infty}^{h} N_{d h}^{h}=H N_{\max } \sqrt{2 \pi e}[I-P(p)]
$$

where $P(p)$ is the probability integral

$$
P(p)=\frac{2}{\sqrt{\pi}} \int_{0}^{p} e^{-u^{2}} d u,
$$


and $h$ is related to $p$ by

$$
p=\frac{1}{\sqrt{2}} e^{-z}
$$

The probability integral $P$ is conveniently tabulated in most handbooks of mathematical tables.

A special case of equation (4) is the total electron content above the peak:

$$
\mathrm{N}_{\mathrm{A}}=\int_{\mathrm{h}} \int_{\max }^{\infty} \mathrm{Nh}=\mathrm{HN}_{\max } \sqrt{2 \pi \mathrm{e}}\left(\mathrm{P}\left[\begin{array}{ll}
\frac{1}{2} & \sqrt{2}
\end{array}\right]\right)
$$

With $\mathrm{H}$ chosen as $100 \mathrm{~km}$ this may be written:

$$
N_{A}=2.82 \times 10^{7} N_{\max }\left(\text { electrons } / \mathrm{cm}^{2} \operatorname{column}\right)
$$

so that a combination of observed content up to $h_{\max }$, plus an evaluation by equation (8), gives an estimate of the total electron content per $\mathrm{cm}^{2}$ column above the observing point.

(Wright, J. W., 1959) "On the Inference of the High Ionosphere from Ground-based Soundings." (Submitted for publication) 


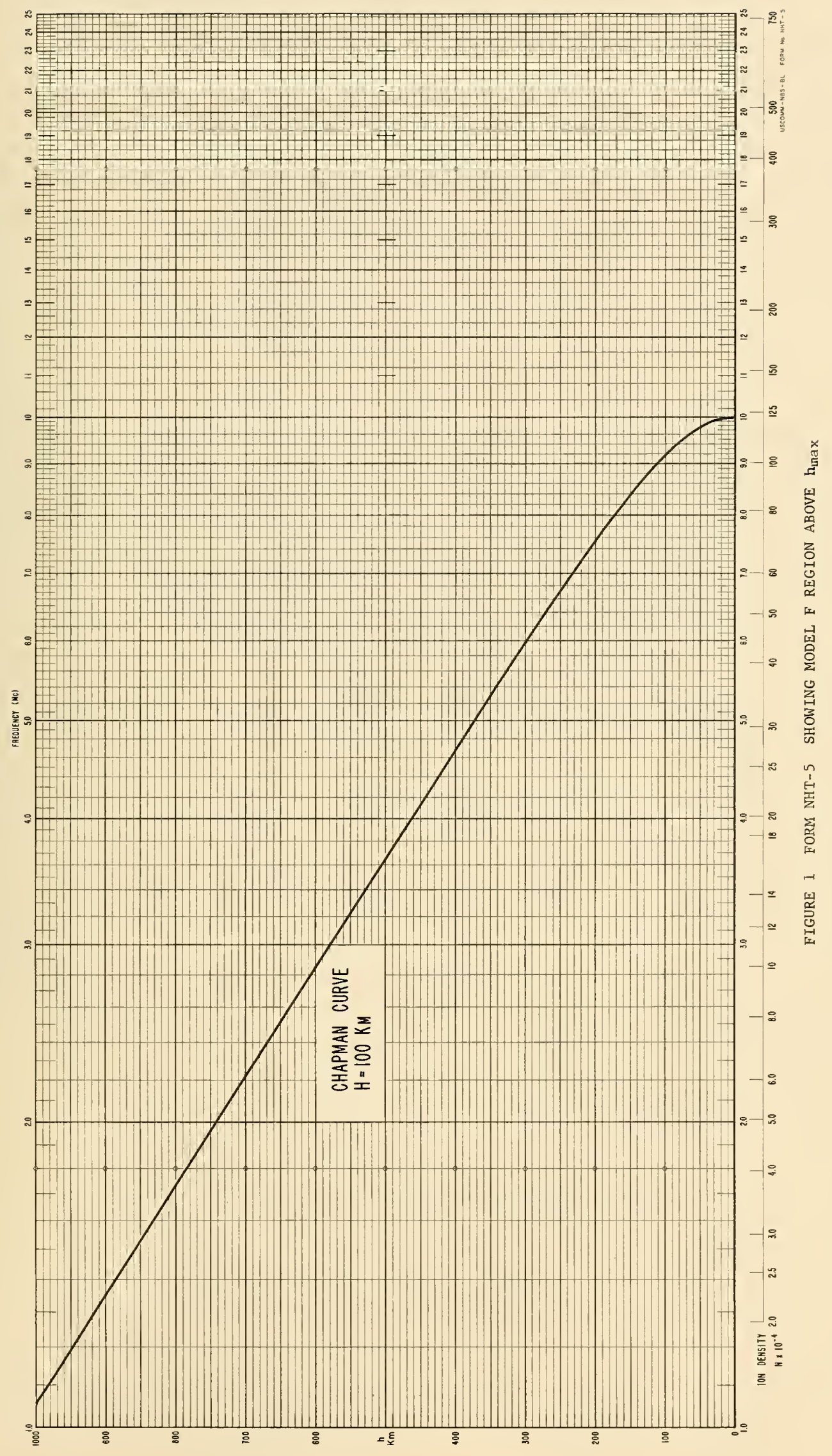



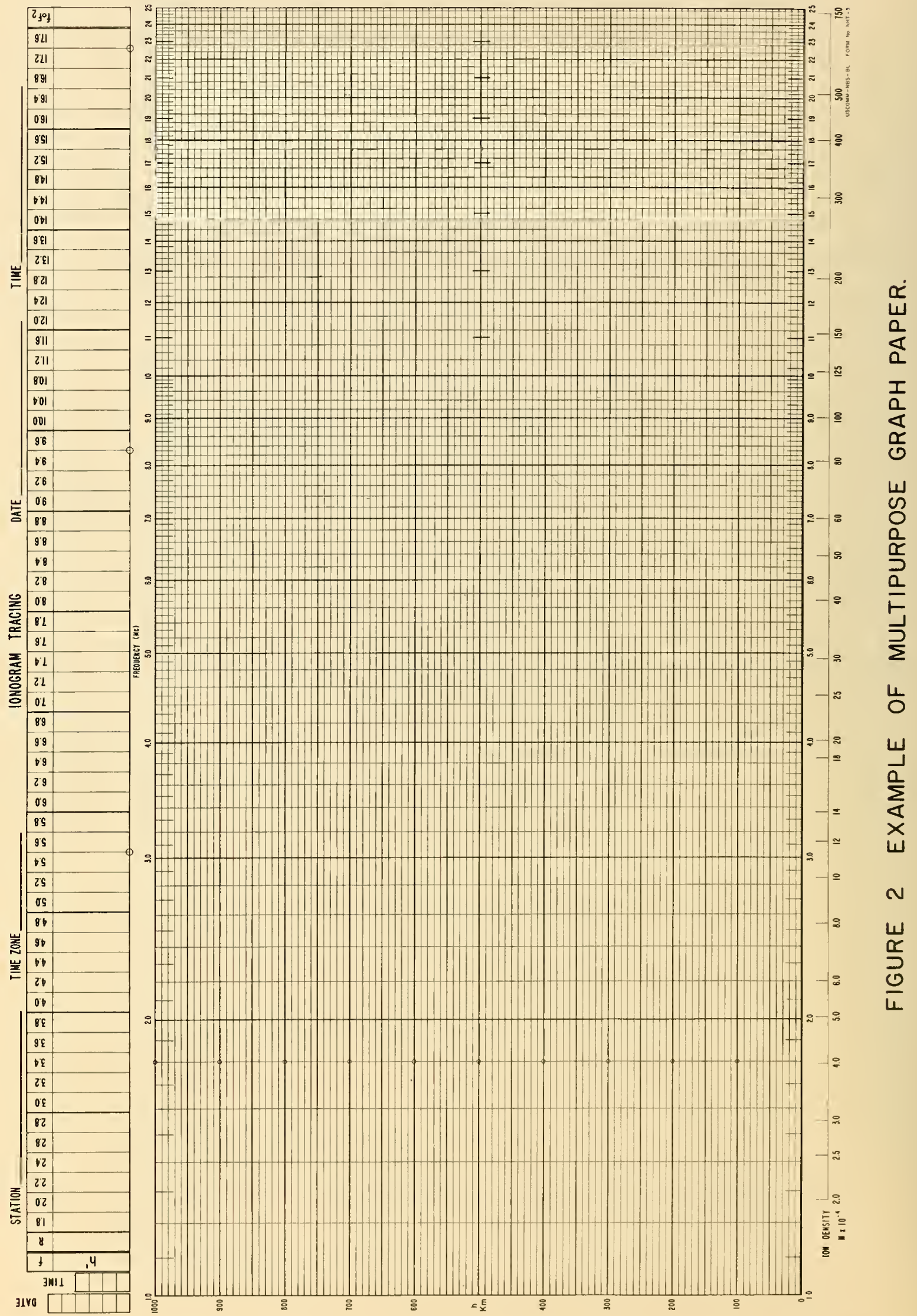


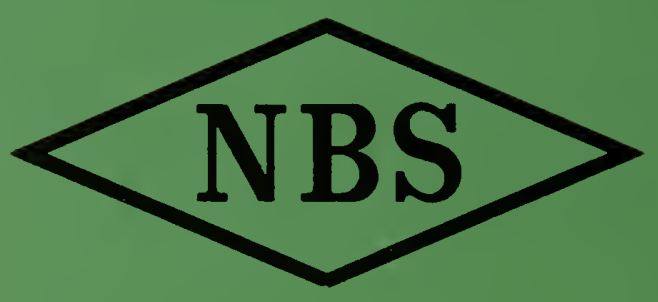

